\title{
Information Technology in Engineering for Sustainable Development
}

\author{
${ }^{1}$ Anyasi, F.I, ${ }^{2}$ Obiazi, A.M.O, ${ }^{3}$ Evbogbai, M.J.E, ${ }^{4}$ Akpaida, V.O.A, \\ ${ }^{5}$ Onianwa, C.U, ${ }^{6}$ Ebegba, D \\ 1,2,3, 4Department Of Electrical and Electronics Engineering, Ambrose Alli University, P.M.B 14, Ekpoma, \\ Edo State, Nigeria \\ ${ }^{5}$ Department of Computer Sciences, Ambrose Alli University, P.M.B 14, Ekpoma. Edo State, Nigeria \\ ${ }^{6}$ Department of Electrical and Electronics Engineering, Petroleum Training Institute, P.M.B, 20, Effurun, Delta \\ State, Nigeria.
}

\begin{abstract}
Interest involves the review of information technology in engineering for sustainable development. This takes a look at the relevance of information technology in Engineering with reference to the several form of information exchange between two or more computers through any of the several methods of interconnections. In modern global economy like Nigeria, I.T are intensively utilized for electronic transactional processing and in supporting various fields like banking, governance, engineering, health, education research fields and education in accomplishing their global and economic task across the nation. The emergence of the global information infrastructure presents extra opportunities challenges for the country. The use of mobile phone in the banking industry, its economic implications, and in general a systematic look into the various forms of mobile banking with emphasis on the security measures that makes the whole process safe for adoption will be outlined with reference to the technology being discussed.

Information technology (IT) has greatly contributed to the development of a new type of entrepreneurship based on creativity, the ability to network, openness to virtual environments and intangible assets, high level of agility immediate responsiveness and the continues accumulation of new knowledge. This makes it imperative for higher and broader skills and competence, through continuous learning, the updating and enlargement of skills. In the long run, there will be improvement for competitiveness, productivity and job creation which are measure of sustainable development.
\end{abstract}

Key words: I.T Technology, Engineering, and sustainable development.

\section{Introduction:}

The advert of information and communication technology remains the driving force for socio-economic development around the world in its charging effects on the way we think. Man-kind has handled information for thousands of years; early technologies include the abacus and printing. The Past forty years, have seen amazingly rapid development of ICT spearheaded by the computer; more recently, cheap microelectronics have permitted the diffusion of this technology into almost all aspects of Daily life and an almost inextricable crossfertilizing and intermingling of its various branches, [1].

Sustainable Development is a global crusade movement, a process rather than an end goal. To achieve and sustain development (sustainable development), revolutionary efficient, reliable and potential tools must be employed.

We use the term information technology or IT to refer to an entire industry. In actuality, information technology is the use of computers and software to manage information. In some companies, this is referred to as Management Information Services (or MIS) or simply as Information Services (or IS). The information technology department of a large company would be responsible for storing information, protecting information, processing the information, transmitting the information as necessary, and later retrieving information as necessary, [2].

Information technology in engineering today is perhaps the fastest evolving field that affects the nation $\square$ seconomy. It is one of the present rapid growing sectors today that has been defined over the years in many ways as that part of technology that is principally concerned with driving positive effect on the economy. In general, information technology means the electronic capture collection, storage, manipulation, transmission, retrieval and presentation of information in form of data, text voice or image and includes telecommunication, internet and office automation functions, [3].

Information system/technology can be any organized combination of people, hardware, software, communications networks, and data resources that collect, transforms, and disseminate information in an 
organization, [4.]. Banks urgently need to improve the ability to think strategically about information technology investments.

Information technology, more than any other factor is clearly the driving force behind the technological revolution of our times. It has affected and permeated every aspect of our daily life, often determine how we live.

Sustainable Development is a global crusade movement, a process rather than an end goal. To achieve and sustain development (sustainable development), revolutionary efficient, reliable and potential tools must be employed. These tools are the Information Technologies in Engineering such as the Internet, mobile phones, emails, micro-computers amongst others.

I.T is new technologies that cannot be ignored in Nigeria especially for development. This is because I.T is one of the main driving force stimulating development and change in the digital age.

\section{Overview Of Information And Communication Technology}

Information and Communication Technology (ICT) is technology that supports activities involving the creation, storage, manipulation and communication of information, together with the related methods, management and application. In other words, ICT enables us to record, store, process, retrieve and transmit information. It encompasses modern technologies such as computers, telecommunications, facsimile and microelectronics.

Information and Communication Technology in today's World refers to those technologies that determine the efficiency and effectiveness with which we communicate, and the devices that allow us to handle information. Information and Communication Technology has however played a very important part in human life. However in the mid- $20^{\text {th }}$ century, the role of ICT increased immeasurably as a result of social progress and vigorous development in science and technology, [5].

In addition, rapid expansion of a mass of diversified information is occurring, which has received the name " information explosion". As a result, the need has arisen for a scientific approach to information and for elucidation of its most characteristic properties which has led to two principal changes in interpretation of the concept of information. Firstly, it was broadened to include information exchange, not only between man and man, but also between machine and machine, as well as exchange of signals in the animals and plants World.

One of the most dramatic advances in communication potential - data communication - is found in the field of computer technology. Since the first development of modern electronic digital computers in the 1940s, computerisation has infiltrated almost every area of society in Nations with advanced technology. Computers are available in many formats for use in industries, businesses, hospitals, schools, universities, transport networks and individual homes. Small or large, a computer network exists to provide computer users with the means of communicating and transferring information electronically. The use of INTERNET has revolutionized access to information for the business world, libraries, education and individuals. A few of the most popular include electronic mail (e-mail), World Wide Web (WWW), file transfer protocol (FTP), USENET, TELNET. Internet and its technology continues to have a profound effect in promoting the sharing of information especially in academic World, making possible rapid transactions among businesses and supporting global collaboration among individuals and organizations [6].

The World Wide Web (WWW) can be described as a library of resources available to computer users through the global internet. It enables the user to view a wide range/variety of information, including magazine, archives, publications and college library resources and current World and business news. WWW resources are organised so that users can easily move from one resource to another. Using IT (Information Technology) learners can absorb more information and take less time to do so. Information Technology (IT) is therefore objective in this research to highlight its significance and importance in the key areas in Nigeria. This paper shall also examine the extent to which it is being used in support of Information delivery and Communication in science and Technology.

The basic idea of information and communication technology is the exchange of information and provision services to a number of end users through the medium of communication (telecommunication) and information technology processing.

Nigerian today is shaped by the advancements in the field of information and communication technology (ICT). Information and communication is integral to human society. In Nigerian communities that existed before colonial rule, people communicated using various instruments and codes such as talking drums, flutes, gongs, town crier and village square meetings. Many historical records are still on walls of caves and especially transmitted through oral tradition. The use of writing and the invention of printing transformed the type and content of records history.

Communications on a universal scale became possible through the use of books, newspapers, and magazines. More recent technological innovations increased further the reach and speed of communications, culminating for now, with digital technology. For several years many researchers have been showing particular interest in information and communication technologies (ICT). For the past two, decades, Nigerian has 
witnessed significant changes that can be traced to ICTs. The multidimensional changes (technical, financial and economic cultural, social and geo-political) have been observed in almost all aspect of life; economics, education, banking, communications, travel [8]. The changes observed in these areas have led to what is now referred to as the knowledge society. ICTs have made it possible to fast access to and distribution of information as well as new ways of doing business in real time at a cheaper cost. The evolution of ICTs has been linked closely to the power and economic boom in Nigeria, and there has been a strong positive correlation between development levels and the adoption of increasingly sophisticated and complex technologies. The advancements in technology has created so many ICT tools that are necessary and useful in the development process. The new technologies have become central to contemporary societies. Government have recognized the role that information and communication technologies (ICTs) could play in socio-economic development and is already putting in place policies and plans to transform the economy into information and knowledge -rich one in a globally competitive marked. This is because ICT has offered the country a window of opportunities to leapfrog the industrialization stage and transform the economy into high value-added information economy that can compete with the advanced economy on the global market. Technology innovations such as the internet, mobile telephony, video calling, voice data and video conferencing, among others have contributed to rapid globalization by supplying infrastructure for trans-world connections. Undoubtedly, the revolution taking place in ICT has been the central and during force of the globalization process.

\section{SUSTAINABLE DEVELOPMENT}

Sustainable Development is a pattern of resource that aims to meet human needs while preserving the environment, so that these needs can be met not only in the present, but also for generations to come, [8]

Sustainable Development simply put is developing for the present future, the process of ensuring that the present development is sustained and maintained for the future. The field of sustainable development can be conceptually broken into three constituent parts; environmental sustainability, economic sustainability and social sustainability. However, this study shall be laying more emphasis on economic and social sustainability process, [8].

The United Nations World Summit outcome document refers to the "interdependent and mutually reinforcing pillars" of sustainable development as economic development, social development and environmental protection. The scheme of sustainable development, at the confluence of three constituent parts is as shown in Figure 1, [9].

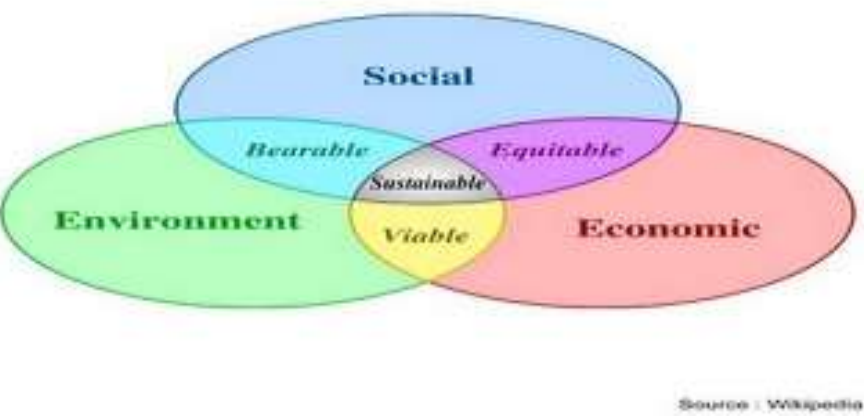

Fig. 1: Sustainable development at the confluence of three constituent parts.

Economic sustainability clearly identified (ICT) Information and Communications Technology integration and participation as key building blocks to help countries achieve development that recognises these interdependent pillars. It emphasizes that in sustainable development, SD everyone is a user and provider of information.

\section{ICT AS TOOLS FOR SOCIO-ECONOMIC DEVELOPMENT}

ICT enhance all forms of information exchange. Observation, learning and decision-making are facilitated and business transactions are expanded and speeded up with ICT. Opportunities can be identified and acted on more easily. Markets lead to business-related efficiencies and fast turn-over, increased productivity, especially in the services sector, and profitability. The parameters of ICT socio-economic development must be considered during ICT policy-making and strategizing. ICT is an important sector of economic activity, achieving high growth rates in developed as well as in developing countries. ICT is also a platform to exchange data, information, knowledge and a tool to implement application (e.g. e-commerce, e-schools, e-health etc.). as such, ICT can play a catalytic role as an enable to development recent developments in technologies, reduction in prices, greater availability of networks and a more user-friendly approach to technologies are strengthening the role of which ICT can play in support of development. ICTs offers the developing world the opportunity to 
„leapfrog $\square$ several stages of development by use of „frontier $\square$ technologies that are more practical, environmentally sound and less expensive than undergoing the traditional stages and cycles of progress to the information society. Cellular service, for example, has become the first and only telephone service for people in many developing countries where it is available much sooner-and much cheaper-than fixed service. Many governments, private sector and civil society members are beginning to recognize the potential offered by ICTS in overcoming structural and historical weakness affecting emerging economies.

The "digital revolution" created by ICTs has the power to transform production processes, commerce, government, education, citizen participation and all other aspects of our individual and collective lives; therefore it can create substantially new forms of economic growth and social development. One the other hand, the digital divide between rich and poor is threatening to exacerbate the existing social and economic inequalities, so the potential costs of inaction are greater than ever before. While there are many examples of the positive transformational impact of ICTs, the inclusion of developing economies into the information society is a far from simple process. Infact, we are only beginning to understand how the application of ICTs relates to the achievement of social goals and economic growth. Others caution the view of ICT for development as a "techno-quick-fix" for solving developing problems that have spanned generation upon generation. Major advances in ICTs combined with rapid growth of global networks such as the internet offer enormous opportunities to narrow social and economic inequalities and support sustainable local wealth creation, and thus help to achieve broader development objectives. For example, "creating a development Dynamic: the nation has enough evidence that illustrate the role of ICTs in generating new economic opportunities, delivering improved healthcare and education, promoting sustainable environmental management, fostering democratic governance by empowering people and organizations, and making government processes more efficient and transparent,

\section{The Internet}

The Internet is a global system of interconnected computer networks that use the standard internet protocol suite (TCP/IP) to serve billions of users worldwide. It is a network of networks that consists of millions of private, public, academic, business, and government networks, of local to global scope, that are linked by a broad array of electronic, wireless and optical networking technologies. The Internet carries a vast range of information resources and services, such as the inter-linked hypertext documents of the World Wide Web (WWW) and the infrastructure to support electronic mail.

Most traditional communications media including telephone, music, film, and television are reshaped or redefined by the Internet, giving birth to new services such as Voice over Internet Protocol (VoIP) and IPTV. Newspaper, book and other print publishing are adapting to Web site technology, or are reshaped into blogging and web feeds.

The Internet has enabled or accelerated new forms of human interactions through instant messaging, Internet forums, and social networking. Online shopping has boomed both for major retail outlets and small artisans and traders. Business-to-business and financial services on the Internet affect supply chains across entire industries.

The origins of the Internet reach back to research of the 1960s, commissioned by the United States government in collaboration with private commercial interests to build robust, fault-tolerant, and distributed computer networks. The funding of a new U.S. backbone by the National Science Foundation in the 1980s, as well as private funding for other commercial backbones, led to worldwide participation in the development of new networking technologies, and the merger of many networks. The commercialization of what was by the 1990s an international network resulted in its popularization and incorporation into virtually every aspect of modern human life. As of 2009, an estimated quarter of Earth's population used the services of the Internet.

The Internet has no centralized governance in either technological implementation or policies for access and usage; each constituent network sets its own standards. Only the overreaching definitions of the two principal name spaces in the Internet, the Internet Protocol address space and the Domain Name System, are directed by a maintainer organization, the Internet Corporation for Assigned Names and Numbers (ICANN). The technical underpinning and standardization of the core protocols (IPv4 and IPv6) is an activity of the Internet Engineering Task Force (IETF), a non-profit organization of loosely affiliated international participants that anyone may associate with by contributing technical expertise.

\section{SERVICES OFFRERED ON THE INTERNET}

Many electronic services are available on the internet. With consistent development of the internet technology itself and with the infrastructure supporting the services offered on the net, the internet continues to grow. The major internet services are as follows; 


\section{Electronic Mail (e-mail)}

This is the most popular and most utilized Internet service especially in the developing countries of the world. A conservative estimate puts the number of people using the e-mail worldwide at more than 90 million people.

E-mail is message sent from one person to another via a computer network. The same e-mail can be sent easily to one address or many addresses. Commercial electronic mail is used for the same purposes as the organization wide mail system. But instead of being limited to members of one organization, the service is made available to the public on subscription bases. E-mail messages are exchanged between customers, suppliers, friends and business partners. E-mail service has cut down on the cost of mailing or sending information thus saving time and money.

E-mail is used as a marketing tool. For example, a company, Dealaday.com uses e-mail to prospect for customers and sends group e-mail to 10,000 user names all customers who have indicated they would like to receive e-mails. With e-mail they receive a $7 \%, 8 \%$ and sometimes $10 \%$ response, unlike $1 \%$ or $2 \%$ response in normal direct marketing.

\section{The World Wide Web (WWW)}

The World Wide Web or the web is one of the Internet's most popular applications and it was launched in 1991. It is a graphical, easy -to-use way to organize and present information, including texts, images, movies, sounds and more. The World Wide Web has generated tremendous popular interest in the Internet.

The www is unique for two reasons. Firstly it is highly interactive media bringing documents in graphics, audio and video. Secondly, it uses hyperlink, which provides connections between different resources It allows users to jump from one page to another. A file in www is called the home page and usually contains a multimedia clip. A page can link you to other web pages and Internet resources with clicks of a mouse. You can view and download any information you need on any home page with the aid of software known as the web browser. The web browser translates a home page address called a URL (Universal Resource Locator) and downloads the home page so that you can see it on the screen. Generally browsers are software used to access and view sites on the World Wide Web. Some of the popular ones are Netscape, Navigator and Microsoft Internet Explorer. Netscape offers info seek and Lycos. Others are yahoo, and WebCrawler. The basic language of the www is hypertext mark-up language [HTML] that is used to determine what the information will look like and point to where you can find the links.

The web is based on a protocol called hypertext transport protocol (http) and covers the entire operation of the web. The http runs on top of the TCP/IP (the usual Internet protocol). As information on the web gets easier to find, it is becoming more useful as a tool for conducting everyday business. As a commercial service, the web is basically used to advertise and sell goods and services, streamline operations and automate customer services. With the help of the web, businesses are wringing out time out of product design speeding up the order and delivery of components, tracking sales by the hour, and getting instant feedback from customers.

The main drawback to the use of the www is that it consumes a lot of space thereby slowing the download time. For example 5 minutes of audio can take 5 megabytes of memory. Therefore the www uses up a lot of hard drive space.

\section{Newsgroups}

A newsgroup is an Internet service whereby people with common interests share information or seeks advice over the Internet. Newsgroups do not operate as e-mail, sent directly to e-mail addresses, but as feed that is sent to specific servers around the world. This feed happens at specific times of the day, not when there is a new message posted to the newsgroup. The institution operating the computer system that provides you with the access to the Internet (Internet Service Provider or a university) selects the newsgroups it wishes to subscribe to, and this is the only newsgroup you will be able to get.

\section{File Transfer Protocol (ftp)}

File transfer protocol (ftp) is an Internet tool used to transfer files between computers and it is the most common method of transferring files on the Internet. Without viewing them as they are transferred the ftp enables you to access file on a remote location on the Internet once you log on to an ftp site, and you are able to access all files on sites and download them if you so desire. It is fairly easy to publish information on the Internet. Many institutions maintain publicly accessible archives of information that they want to share with others.

\section{Telnet}

Telnet is an Internet service that allows you to connect to a remote computer to use specific databases or other applications available on that computer. 
Telnet is one of the first applications widely used on the Internet. Many telnet applications are now available on the World Wide Web where they are easier to use..

\section{Internet Conference}

This is an Internet service whereby different techniques are used to allow people to discuss topics of mutual interest. A conference can be as simple as sending e-mail to many different people or as complex as arranging to have people link different cities, see images of each other and hear each other talk in real time- that is video conferencing. Internet conferencing is possible, but the technology becomes more complex and the speed of the connection becomes more important as you go from text only, to transmitting sound and video in real time. Internet conference brings about tremendous savings on travelling, time and money.

\section{Internet Telephony}

This is a service in which you can use the Internet as a voice telephone line. With some types, both you and the person you are calling must have an Internet connection and be online at the time you wish to talk. Some companies also offer Internet-to-telephone services where from your computer you can call any telephone number in the world. Internet telephone services are inexpensive when you compare them with the conventional cost of telephone services. If your organization spends a lot of money on long distance telephone calls, this might be a good option for you. There are growing numbers of companies providing Internet telephone services.

\section{Internet Fax}

Internet fax is a service that takes a special type of e-mail message and sends it to a fax machine specified in the message. The message can be faxed to a computer (Internet-to-Internet).

\section{Listserv}

Listserv is an Internet application that allows subscribers to send an email that will be received by all people who subscribe to the Listserv. Subscribing to the list and all other transactions are handled through email. Listserv are a powerful and inexpensive way for people with shared interests to communicate quickly and cheaply with an entire group of people. Sending an announcement to a listserv is like immediately publishing or broadcasting your remarks. Many organizations are happy to host listserv that conform to their interests .Because of the different types of software, you will often hear listserv called by other names such as listproc or major-domo

\section{Gopher}

The gopher is an Internet service of making text- only material available over the Internet so it can be viewed online. Gopher servers were widely used before the advent of the World Wide Web, and there are still many in operation. They can be accessed through the web browser.

\section{Internet Relay Chat (IRC)}

This is the multi-user chat system where people convene on channels (Virtual Place usually with a topic of conversation) to talk in groups, or privately. In other words IRC allows you to talk to other IRC users worldwide in real time via your keyboard.

\section{BENEFITS OF THE INTERNET}

Basically and generally, the benefits derivable from the utilization of the internet are mainly as follows;

\section{Speed/Time Saving}

The speed of transmission on the internet is the significant benefit of the internet. A letter or document that could take days to arrive by regular mail can be sent to the other side of the World in minutes. Likewise searching through a card catalogue at a library can be a time consuming, tedious process, but you can search an online version of the same catalogue in a fraction of time. The speed of transmitting information naturally saves time and money.

\section{Breadth/ Reach}

The internet gives you access to a vast collection of databases, documents, computer software; these and any kind of information can be stored electronically.

\section{Cost Saving}

Exchanging information via the internet is less expensive than using a telephone or fax machine especially where telephone access fees are high. Likewise, marketing and advertising your products and services on the internet can be less expensive than using conventional printing and document delivery method. 


\section{Two-way Communication}

Audiences now have the means to respond directly to sources of information, research and opinion.

\section{Trading}

The internet provides the opportunity for purchase and sale of goods and services. Specifically, the internet through e-commerce has provided the business community, among others the following benefits;

- Improved response time to clients' request.

- Eased the process of concluding deals and financial transactions.

- Increase consumers' convenience and choice.

- Improved customers' service.

- Reduced price.

- Improved competitive position.

- Extended market reach.

\section{E-GOVERNMENT TRANSFORMATION}

E-Government \{from electronic government, also known as e-gov, digital government ,online government or in a certain context transformational government $\}$ refers to the use of internet technology as a platform for exchanging information providing services and transacting with citizens, business, and other arms of government. E- Government may be applied by the legislature, judiciary, or administration, in order to improve internal efficiency, the delivery of public services, or processes of democratic governance. The primary delivery models are Government- to-Business $\{\mathrm{G} 2 \mathrm{~B}\}$ and Government- to-Employees $\{\mathrm{G} 2 \mathrm{E}\}$ within each of these interaction domains, four kind of activities takes place:

* Pushing information over the internet, e.g.: regulatory services general holidays, public hearing schedules, issues briefs, notifications e $\mathrm{t} c$.

* Two-way communications between the agency and the citizen, a business, or another government agency. In this model, users can engage in dialogue with agencies and post problems, comments, or request to the agency.

* Conducting transactions, e.g. lodging tax returns, applying for services and grants.

* Government, e.g.: Online polling, voting, and campaigning. The most important anticipated benefits of egovernment include improved efficiency, convenience, and better accessibility of public services.

While e-government is often the OUGHT OF AS "Online government" or "internet- based government", many non- internet" technologies can be used in this context. Some non internet forms include telephone, fax, PDA, SMS text messaging, MMS, wireless networks and services, Blue boot, tracking systems, biometric identification, identity cards, smart cards and applications: polling station technology \{where non - Online evoting is being considered\}, TV and radio- based delivery of government services, email, online community facilities, newsgroups and electronic mailing list, Online chat, and instant messaging technologies. There are also some technology -specific sub-categories of e- government, such as m- government \{mobile government , u- government \{ubiquitous government\}, and g- government \{GIS/GPS applications for e- government\}. EGovernment is the use of information technology to provide citizen and organizations with more convenient access to government information and services and to provide delivery of public services to citizen, business partners, and those working in the public sector. The initial part of implementation of e- government is "computerization" of public offices enabling them by building their capacity for better services delivery and bringing kin good government using technology as a catalyst and the second part is provision of citizen centric services through digital media like developing interactive government portals.

\section{ELECTRONIC TICKET SERVICES}

An electronic ticket or e-ticket is used to represent the purchase of a seat on a passenger airline, usually through a website or by telephone. This form of airline ticket rapidly replaced the old paper \{from close to zero to $100 \%$ in about 10 years \} and became mandatory for IATA members as of June 1, 2008. During the last years, where paper tickets were still available, airlines frequently charged extra for issuing them. E-tickets are also available for certain entertainment venues. Once a reservation is made, an e-ticket exists only as a digital record in the airline computers. Customers usually print out a copy of their receipt which contains the record locator or reservation number and the e-ticket number.

Electronic tickets are introduced in road, unbar or rail public transport too. To check in with an $\boldsymbol{E}$ TICKET, the passenger usually comes to the check - in counter and presents the confirmation or reservation code. In some airlines its not even necessary to present the code, as the reservation is confirmed solely on the basis of the passenger identity, which may be proven by a passport or the matching credit card.

* Online/telephone /self - service check- in.

* Early check-in

* Printing boarding passed at airport kiosks and at locations other than am airport.

* Automated refunds and exchanges online, by telephone and at kiosks. 
Several web sites exist to help people holding e- tickets accomplish online check -in advance of the twenty four - hour airline restriction. These sites store a passenger $\square$ flight information and then when the airline opens up for online check-in the data is transferred to the airline and the boarding pass is emailed back to the customer.

\section{E- HEALTH AND TELEMEDICINE SERVICES}

The urgent need for e- health and telemedicine made possible the inception of simple telemedicine links based on e- mail to support doctors in isolated hospitals and then puts them in touch with specialists in tertiary hospitals in the industrialized world, who donate their time and expertise by providing free advice by email on the diagnosis and management of patients. This store and forward still image telemedicine system is based on the British Defence medical services telemedicine system which has been used word wide in both military and civilian settings over all the last 5 years. It uses straight forward e-mail protocols to preserve patient confidentiality and to facilitate archiving of referrals.

The Swinfen charitable trust started operating its first telemedicine link in support of the lone orthopedic surgeon at the centre for the rehabilitation of the paralyses in saver in July 1999. This telemedicine link was carefully evaluated to assess its effectiveness. In this early period of telemedicine, the information was transmitted over ordinary telephone lines using a 19. 2kbits/sec modern as at October 2002. The benefits included establishing the diagnosis, providing reassurance to the patient and referring doctor to have beneficial to the patient $89 \%$ of cases. The benefits included establishing the diagnosis, providing reassurance to the patient and referring doctors, and significant changes of management.

\section{ELECTRONIC BANKING USES AND INITIATIVES IN NIGERIA}

E-banking and mobile banking refers to provision of banking and financial services with the help of electronic systems such as the internet and other computer networks. Most banks today have Electronic systems to handle their daily voluminous tasks of information retrieval, storage and processing. Irrespective of whether they are automated or not, banks by their nature are continually involved in all forms of information management on a continuous basis. The computer is of course an established tool for achieving a competitive edge and optimal resources allocation. The most obvious banking application of computers is to customer service. Computerized banks respond immediately to request from customer for statement of accounts, balance and account activity enquiries. With signature and image verification systems, the take to offer typical cashier services like receiving and paying out of cash, is minimized.

With advent of Automated teller machines (ATM), banks are able to serve customers outside the banking hall. Furthermore, computers help banks to reduce the cost of doing business. Although, the effectiveness of the ICT deployment in banks is another matter, the fact remains that ICT usage is now a reality. This is to be expected in view of the huge amount of information being handled by banks on a daily basis. On the customer $\square \mathrm{s}$ side, cash is with drawn or deposited, cheques are deposited or cleared, statement of accounts are produced, etc. At the same time, facilities, interest, deposits and other financial control information. ICT investment, by banks include ICT infrastructure such as Hardware, software, Networking (local, wide Area and the internet). For E-banking to be effective these areas must be well managed. Banking software can be described as the heart and soul of a bank $\square \mathrm{s}$ ICT infrastructure. Computers give banks the ability to quickly respond to market trends, change in the business environment, [10].

E-banking can also be refers to the effective deployment of ICT by banks. E-banking is about using the infrastructure of the digital age to create opportunities both local and global. E-banking enables the dramatic lowering of transaction costs, and the creation of new types of banking opportunities that address the barriers of time and distance. Banking opportunities are local, global and immediate in E-banking. The benefits of Electronic banking compasses a broad range of functions and include: Electronic mail (email) improves communication between individuals and the bank, within the bank, with the bank and external parties. The availability of online information provides bankers and customers with a powerful vehicle for research. If a banking function does not require physical interaction, it may derive the

\section{CUSTOMERS' SECURITY}

In some areas, multiple security cameras and security guards are a common feature. The New York state comptroller $\square \mathrm{s}$ office has criticized the New York states department of banking, for not following through on safety inspections of ATMs high crime areas. Critics of ATM operators assert that the issue of customer security appears to have been abandoned by banking industry. It has been suggested that efforts are now more concentrated on deterrent legislation than on solving the problem of forced withdrawals. As least as far back as July 30, 1986, critics of the industry have called for the adoption of an emergency Pin system for ATMs where the user is able to send a silent alarm in response to a threat, [11]

The emergence of mobile banking technology systems has implications for the general discussions about mobile telephony in the developing world. For example, it underscores the way the device blurs the domestic and the productive spheres, the social and the transactional. Each transaction is influenced by (and 
reinforces) the structural position of the people in broader informational networks. The latest case of $\mathrm{m}$-banking systems is a reminder that an understanding of the role of the mobile in mediating both social and economic transactions, sometimes simultaneously. Existing theory about the significance of mobile communications in the developing world has focused on voice and text messaging, [12]. But the emergence of mobile banking also underscores how, occasionally, innovations emerge from unexpected places and have the capability of reconfiguring the significance of a technology to its users. Mobile theory must keep pace, accounting for $\mathrm{m}$ banking systems along with other capabilities enabled by this increasing flexible technology, offering a way to lower the costs of moving money from place to place and opening a way to bring more users into contact with formal financial systems. M-banking systems may prove to be an important innovation for the developing world. However, the true measure of that importance requires multiple studies using multiple methodologies and multiple theoretical perspectives before the issue of its economic implication can be fully outlined.

\section{RELEVANCE OF I.T FOR BETTER GOVERNMENT, [13-14]}

A planned and stepwise introduction and use of ICTs in government can lead to the transformation of the public sector into an open, accessible, information, helpful and user friendly service for the people. This means going beyond the usual office productivity applications. Some of the impacts and relevance are:

* Increase in service expectations by the public and increasing satisfaction of these expectations.

* Increase in the efficiency and effectiveness of government.

* Greater access to and availability of public information. Less needs to travel and queue.

* Automation of most government services and transaction.

* Increases participation in government.

* Increase public satisfaction and trust in government.

\section{Conclusion:}

From all indicates, the economic impact that public private partnership has made in the I.T sub-sector, within its relatively short existence has been tremendous and this has encouraged a health range of I.T activities across the country. It provides the backbone for other industries and almost every aspect of the national economy. The internet services have allowed people to always gain access to their information for business transactions. The mobile phone in Nigeria has made it possible for people to have access to phones that were previously the exclusive preserve of the wealthy. In addition with globalization, technological innovation progressively becoming a reality in given number countries including Nigeria. The emergence of the global information infrastructure presents extra opportunities challenges for the country. Information technology (I.T) has greatly contributed to the development of a new type of entrepreneurship based on creativity, the ability to network, openness to virtual environments and intangible assets, high level of agility immediate responsiveness and the continues accumulation of new knowledge. This makes it imperative for higher and broader skills and competence, through continuous learning, the updating and enlargement of skills. In the long run, there will be improvement for competitiveness, productivity and job creation. The rapid diffusion of the Internet, of mobile telephony and of broadband networks all demonstrates how pervasive the technology has become. The development of any developing nation like Nigeria depends on the overall progress in its information technology (I.T) sub-sector. I.T serves as a tool for achieving millennium development goals in Nigeria and with the help of I.T Nigeria has recorded an average of six percent annual economic growth rate in the last eight years. Governance and the delivery of public services in the nation's economy performed more efficiently through the use of I.T which includes mobile and fixed-wireless telephony, the internet broadband and wide area networks.

Finally, in the information society where progress and power depends on information and knowledge, the role technology becomes even more critical.

\section{References}

[1] F.I, ANYASI, A.M.O, OBIAZI, AND M.J.E, EVBOGBAI. "INFORMATION TECHNOLOGY IN ENGINEERING" INTERNATIONAL CONFERENCE ON RESEARCH AND CAPACITY BUILDING" $15^{\mathrm{TH}}$ TO $16^{\mathrm{TH}}$ SEPTEMBER, 2011. PAGE 133. UNIVERSITY OF GHANA, EAST LEGON, ACCRA GHANA.

[2] F.I, ANYASI AND A.L, IMOIZE L "INFORMATION TECHNOLOGY AND THE BUSINESS COMMUNITIES: A CASE STUDY OF SMALL-SCALE BUSINESS ENTERPRISES IN NIGERIA” RESEARCH JOURNAL OF APPLIED SCIENCE ENGINEERING AND TECHNOLOGY (RJASET) 2010 Volume: 2, Issue: 1, Page no: 45-49. . INDIA.

[3] Full Issue available at the following link http://www.maxwellsci.com/archives.php?jid=RJASET

[4] Full text available at the following link. http://www.maxwellsci.com/print/rjaset/v2-45-49.pdf

[5] F.I, ANYASII AND P.A, OTUBU. "RELEVANCE OF INFORMATION AND TELECOMMUNICATION TECHNOLOGY IN NIGERIA ECONOMY” INTERNATIONAL JOURNAL OF SUSTAINABLE DEVELOPMENT: VOL 2, NO 3 (2009) 15-20. ACCRA GHANA.

[6] F.I, ANYASI. AND P.A, OTUBU. "MOBILE PHONE TECHNOLOGY IN BANKING SYSTEM: IT'S ECONOMIC EFFECT. INTERNATIONAL JOURNAL OF PURE AND APPLIED SCIENCE: VOL 2, NO 2 (2009) 1-6. ACCRA GHANA.

[7] A.N, ANIEKWE AND F.N, OGBEIDE,F.N, "Information Technology And Technological Development in Africa" Journal of Engineering Science and Applications. Vol 3(2): 2003. Pp 77-88. 
[8] L.A, OGUNSOLA, AND W.A, ABOYADE, "Information and Communication Technology in Nigeria": Revolution or Evolution. 2005. PP.7-14.www.nigeriabussiness info.com/telecoms(www.Ask.com)

[9] A.U, NWABUEZE, AND R.E, OZIOKO, "Information and Communication Technology for Sustainable Development in Nigeria" 2011.

[10] A, MAIYE AND K, Mc GRATH, “ ICTs and sustainable development: a capability Perspective; AMCIS 2010 proceedings, paper 541. Available at http://aisel-aisnet.org/amcis2010/541

[11] S.R, THEODORE “Wireless Communications Principles and Practices" By prentice - Hall of India, 2003. Pp. 25, 105.ISBN: 81203-2381-5

[12] Wikipedia, the free encyclopedia http://en:wikipedia.org/wiki/mobile banking-7/16/2008

[13] http://www.articlbase.com/communication-articles/mobile-banking-technology-205170.8/17/2008

[14] Wikipedia, the free encyclopedia "http.//en.wikipedia.org/wiki/telephone banking-7/16/2008

[15] Wikipedia, the free encyclopedia. http://en.wikipedia.org/wiki/automated-teller-machine7/16/2008. 